\title{
OS SENTIDOS DO LUTO NA PANDEMIA DE COVID-19 NO BRASIL
}

\section{THE MEANINGS OF GRIEF IN THE COVID-19 PANDEMIC IN BRAZIL}

\author{
Ilka de Oliveira Mota ${ }^{1}$ \\ Erich Lie Ginach ${ }^{2}$
}

Resumo: Tomando um corpus heterogêneo construído com recortes de falas e gestos do Presidente da República, charges e discursos dos e sobre os memoriais que homenageiam vítimas da pandemia, nosso objetivo é compreender como o luto vem sendo significado na e pela sociedade brasileira no contexto da pandemia da COVID-19. Ao mesmo tempo que mata centenas de milhares de brasileiros, a pandemia de COVID-19 impõe restrições aos velórios, que são parte fundamental da necessária significação do luto. No Brasil, a sociedade se posiciona de diferentes formas diante desse quadro. O Presidente Bolsonaro silencia a pandemia e o luto e banaliza a morte. Cartunistas denunciam essa política fascista e negacionista. Outros artistas criam memoriais em forma arquitetônica ou biográfica pelos quais os enlutados podem significar a perda dos entes queridos de modo novo e estético. Essas expressões artísticas constituem formas de resistência à política negacionista, à banalização da morte e à própria morte. O trabalho mobiliza categorias teóricas da Análise Materialista do Discurso e da Psicanálise.

Palavras-chave: COVID-19; luto; resistência.

\begin{abstract}
Taking a heterogeneous corpus built with clippings of speeches and gestures by the President of the Republic, cartoons and discourses of and about the memorials honoring pandemic victims, our objective is to understand how grief has been signified in and by the Brazilian society in the context of the pandemic of COVID-19. While it kills hundreds of thousands of Brazilians, the COVID-19 pandemic imposes restrictions on funerals, which are a fundamental part of the necessary signification of grief. In Brazil, society positions itself in different ways in relation to this situation. President Bolsonaro silence the pandemic and grief and trivialize death. Cartoonists denounce this fascist and negationist policy. Other artists create memorials in architectural or biographical form by which the bereaved can signify the loss of loved ones in a new and aesthetic way. These artistic expressions constitute forms of resistance to the negationist policy, the banalization of death and death itself. The work mobilizes theoretical categories of the Materialist Discourse Analysis and of the Psychoanalysis.
\end{abstract}

Keywords: COVID-19; grief; resistance.

\section{INTRODUÇÃO}

Desde que a Organização Mundial da Saúde (OMS) anunciou a pandemia de COVID-19 em 11 de março de 2020 (SOCIEDADE BRASILEIRA DE MEDICINA DE FAMÍLIA E COMUNIDADE, 2020), os países foram obrigados a adotar políticas de contenção da doença, como lockdowns, fechamento de fronteiras e aeroportos,

\footnotetext{
${ }^{1}$ Professora Associada II da Universidade Federal de São Carlos (UFSCar), campus Lagoa do Sino, Buri, SP, Brasil. ilkamotaeducacao@gmail.com

Orcid: https://orcid.org/0000-0001-6637-4310

${ }^{2}$ Mestre em Linguística pela Universidade Estadual de Campinas (UNICAMP), Instituto de Estudos da Linguagem (IEL), Departamento de Linguística. erichginach@gmail.com

Orcid: https://orcid.org/0000-0001-9582-6427
} 
campanhas de distanciamento social, uso de máscara e restrições aos velórios. O velório é um ritual necessário para a vivência subjetiva e social do luto; restringi-lo trouxe um sofrimento adicional aos sujeitos enlutados. No Brasil, a situação foi agravada porque o governo do Presidente Jair Bolsonaro, alegando prejuízos para a economia, atua contra as medidas restritivas e não mostra respeito aos doentes e mortos.

Tendo como referencial teórico-metodológico a Análise de Discurso de cunho materialista e a Psicanálise, o objetivo deste artigo é analisar como o luto pela COVID19 é significado no Brasil em diferentes manifestações linguageiras, sejam discursos verbais ou não-verbais produzidos pelo governo federal e por outros setores da sociedade. Da Análise de Discurso são mobilizadas as noções teóricas de formação discursiva, forma-sujeito e silenciamento. $\mathrm{O}$ conceito de luto é compreendido segundo os estudos da Psicanálise.

O corpus, de natureza heterogênea, é constituído por: i) falas sobre a COVID-19 enunciadas pelo Presidente Jair Bolsonaro; ii) ações e gestos do Presidente; iii) charges de Duke, Carlos Latuff e Renato Aroeira e iv) discursos dos e sobre os memoriais em homenagem às vítimas fatais da pandemia.

\title{
1. OS SENTIDOS DO LUTO
}

\author{
"Oh, pedaço de mim \\ Oh, metade amputada de mim \\ Leva o que há de ti \\ Que a saudade dói latejada \\ É assim como uma fisgada \\ No membro que já perdi” \\ Chico Buarque, "Pedaço de mim"
}

A pandemia de COVID-19 fez o mundo se confrontar com perdas, reais ou imaginárias (PENNA, 2015). Perdas importantes como a impossibilidade ou restrição temporária de sair, circular, abraçar entes queridos, vivenciar a rotina escolar. Perda do emprego, do comércio, perda do direito de ir e vir e, finalmente, mas não menos importante, perda de pessoas com quem estabelecemos laços e afetos.

Mobilizamos o conceito de luto formulado por Freud (2006), segundo o qual toda perda - que não se restringe à morte de alguém - demanda um luto, trazendo um breve debate que considera as investigações sobre o trabalho do luto que se acumularam no decorrer do último século. Para Freud (2006, p. 103), o luto consiste na

[...] reação à perda de uma pessoa amada, ou à perda de abstrações colocadas em seu lugar, tais como a pátria, liberdade, um ideal etc. Entretanto, em algumas pessoas - que por isso suspeitamos portadoras de uma disposição patológica — sob as mesmas circunstâncias de perda, surge a melancolia, em vez do luto. Curiosamente, no caso do luto, embora ele implique graves desvios do comportamento normal, nunca nos ocorreria considerá-lo um estado patológico [...], pois confiamos em que, após determinado período, o luto será superado, e considera-se inútil e mesmo prejudicial perturbá-lo.

Freud diferencia o luto "normal" do melancólico, que envolve um processo lento e doloroso e deve ser elaborado para que o sujeito encontre um objeto substitutivo do que perdeu. O luto tem importância capital na ressignificação do vazio que a perda instaura no sujeito.

Um ponto crucial no tema do luto é o fato de que não envolve somente a perda do objeto amado, mas aquilo do sujeito que se foi com a perda do objeto, sua representação 
libidinal investida. O luto resiste à prova da realidade (ALLOUCH, 2004). A epígrafe acima, extraída da canção "Pedaço de mim", retrata o estado psíquico do enlutado: a perda de um ser amado é também a perda do lugar que o sobrevivente ocupava na vida do morto (um pedaço de mim foi junto com o objeto perdido), diferentemente do melancólico, que desconhece tanto a natureza do objeto perdido como a origem da perda (FREUD, 2006).

Allouch (2004) é um dos pesquisadores da atualidade que se dedicam ao tema do luto. Esse psicanalista retoma o texto seminal freudiano, "Luto e melancolia", e o interroga. Em síntese, Freud propõe um luto finalizado e elaborado pela substituição do objeto perdido por outro objeto, substituto do anterior. A substituição de um objeto por outro consumaria o luto. A crítica de Allouch reside justamente nesse ponto: a substituição do objeto perdido por outro é um modo de negar a perda, negação que apresenta um caráter perverso. O que está em jogo no luto é uma perda de um "pedaço de si" cujo acento recai sobre o "si", que é diferente do "eu"/ "mim" e do "tu"/ "ti". Ele é da ordem dos dois e de nenhum, ponto de enlace e indefinição entre sujeito e objeto, seguindo a lógica moebiana que Lacan ensina. Em outros termos, a perda não é o do objeto, mas sim daquilo do objeto que é também do sujeito.

Todo luto, seja individual ou coletivo, demanda a presença do outro, condição sine qua non para que haja a ritualização da perda. Nas palavras de Penna $(2015$, p. 17), "[u]ma perda sempre precisa ser testemunhada, reconhecida pelo outro para tornar-se real", a fim de que se inicie o processo de sua elaboração e historicização.

\begin{abstract}
Nossas perdas se infiltram e se coligam com as perdas alheias, fazendo com que sua realização deixe de ser um trabalho individual e demande expressão coletiva. Perdas coletivas, como a que experimentamos no contexto da epidemia de Covid, assim como perdas individuais, como a que sentimos em relação ao neto de Lula, ou perdas anônimas dos que hoje morrem sob a violência impune, não são só um assunto político, motivo de raiva, negação ou de culpa, mas de esforço e convite a que nos reconheçamos nas séries sociais de luto que nos formam e nos determinam. (DUNKER, 2020, negrito nosso).
\end{abstract}

Além da presença do outro no processo de elaboração do luto, as cerimônias e manifestações fúnebres são necessárias para que haja a crença de que uma pessoa realmente não existe mais no corpo prestes a ser enterrado (KEHL, 2020). No caso específico das mortes por COVID-19, temos um agravante: por causa do risco de contaminação, os sujeitos se veem impossibilitados de se despedir pela última vez e enterrar seus mortos, resultando em um luto particular, destituído de rituais coletivos que possibilitem a inscrição (elaboração psíquica) da experiência da perda.

Rivière (1997) traz considerações importantes sobre os rituais fúnebres coletivos. Para o autor,

[...] os ritos devem ser sempre considerados como conjunto de condutas individuais ou coletivas, relativamente codificadas, com um suporte corporal (verbal, gestual, ou de postura), com caráter mais ou menos repetitivo e forte carga simbólica para seus atores e, habitualmente, para suas testemunhas, baseadas em uma adesão mental, eventualmente não conscientizada, a valores relativos a escolhas sociais julgadas importantes e cuja eficácia esperada não depende de uma lógica puramente empírica que se esgotaria na instrumentalidade técnica do elo causa-efeito. (RIVIÈRE, 1997, p. 30, negrito nosso).

O ritual se prolonga para além do ato em si e adquire características simbólicas. Do ponto de vista do psiquismo, tem um lugar fundamental na elaboração do luto coletivo. Em síntese, ele é um modo de reconhecimento sócio-histórico que possibilita o necessário trabalho de luto coletivo em um país. Porém, caso o luto se torne obstinado, existe a possibilidade de o indivíduo ficar paralisado durante toda a vida. 
Compreende-se que se esse trabalho de desinvestimento que deve seguir-se à morte do outro não se cumprir, e se o eu ficar assim simbolizado em uma representação coagulada, o luto se eterniza em um estado crônico, que paralisa a vida da pessoa enlutada durante vários anos, ou até durante toda a sua existência. (NASIO, 1997, p. 29).

Por outro lado, a ausência, o desprezo ou a negação do luto pode gerar um trauma coletivo na subjetividade de toda uma geração. Na Psicanálise, o trauma é compreendido como Real não simbolizado. As tentativas de esquecer eventos traumáticos coletivos resultam em sintoma social. Para Kehl (2009, p. 29), "[...] quando uma sociedade não consegue elaborar os efeitos de um trauma e opta por tentar apagar a memória do evento traumático, esse simulacro de recalque coletivo tende a produzir repetições sinistras".

Todas as sociedades que passaram por tentativas de esquecimento da experiência traumática tiveram como resultado sintomas sociais como "[...] melancolia, má consciência, desrealização da experiência histórica, além do inevitável retorno do recalcado, expresso pela proliferação de grupos de jovens neonazistas a partir da década de 1980.” (KEHL, 2009, p. 28). No Brasil, a sociedade sente até hoje os sintomas da Ditadura Militar que não foram reparados nem elaborados coletivamente.

Acrescente-se que uma sociedade pautada no lucro e na destruição de direitos trabalhistas e sociais dificilmente demonstrará empatia pelos seus mortos, enlutados e por tragédias pandêmicas como a que assistimos hoje: ela tende, isso sim, a ser indiferente e, em alguns casos, hostil a temas como luto, sofrimento e traumas coletivos. Em sociedades capitalistas neoliberais, os sujeitos estão em um eterno desamparo. Como diz Birman (2017, p. 53), “[...] pelo desmantelamento do Estado do bem-estar social, com a hegemonia do modelo neoliberal na economia e a mundialização do mercado, o desamparo das pessoas tem atingido limiares inimagináveis.”

\section{O LUTO NEGADO}

O discurso é efeito de sentidos entre locutores historicamente situados, lugar onde se observa a relação entre língua e ideologia. Essa relação constitui no dizer regiões de sentidos ou Formações Discursivas (FDs), que correspondem às diferentes formações ideológicas de uma formação histórica. Cada FD é um domínio de saber que "[...] funciona como um princípio de aceitabilidade discursiva para um conjunto de formulações (determina 'o que pode e deve ser dito') e também como princípio de exclusão do não dizível" (COURTINE, 1982, p. 249-250, tradução nossa). Ao enunciar, o sujeito se projeta imaginariamente na forma-sujeito da FD que o domina, assumindo seus sentidos enquanto sistema de evidências e de significações percebidas, aceitas e experimentadas (PÊCHEUX, 1988). O que está em questão é a posição-sujeito, não "[...] uma forma de subjetividade, mas um 'lugar' que ocupa para ser sujeito do que diz" (ORLANDI, 1999, p. 49).

O luto, como vimos, é uma forma sócio-histórica de simbolização da perda do objeto amado. Ao significar o luto e ser significado por ele, o sujeito assume a posiçãosujeito do enlutado, em relação à qual se constitui uma FD em que se pode e se deve prantear os mortos. Nessa FD, desrespeitá-los ou tratá-los como supérfluos e ignoráveis são posições evitadas, não enunciadas.

O Presidente Jair Bolsonaro fez uma série de declarações que revelam a posiçãosujeito em que se sustenta para falar e agir em relação à COVID-19 e suas consequências. Os jornalistas Camilo Vannuchi (2020) e Gabriela Oliva (2021) compilaram uma série desses enunciados, dentre os quais selecionamos os seguintes: 
E1: "Está superdimensionado o poder destruidor desse vírus. Talvez esteja sendo potencializado até por questões econômicas." (9 mar. 2020)

E2: "Outras gripes mataram mais do que essa." (11 mar. 2020)

E3: "Esse vírus trouxe uma certa histeria e alguns governadores, no meu entender, estão tomando medidas que vão prejudicar e muito a nossa economia." (17 mar. 2020)

E4: "Gripezinha" (20 mar. 2020)

E5: "Pelo meu histórico de atleta, caso fosse contaminado pelo vírus, não precisaria me preocupar. Nada sentiria. Ou seria, quando muito, acometido de uma gripezinha ou resfriadinho. [...] Algumas poucas autoridades, estaduais e municipais, devem abandonar o conceito de terra arrasada, a proibição de transportes, o fechamento do comércio e o confinamento em massa." (24 mar. 2020)

E6: "Brasileiro pula em esgoto e não acontece nada" (26 mar. 2020)

E7: “O maior remédio para qualquer doença é o trabalho. [...] Não podemos agir dessa maneira irresponsável. [...] Vão quebrar o Brasil por conta do vírus?” (27 mar. 2020)

E8: "O vírus está aí. Vamos ter que enfrentá-lo, mas enfrentar como homem, porra. Não como um moleque. Vamos enfrentar o vírus com a realidade. É a vida. Todos nós iremos morrer um dia." (29 mar. 2020)

E9: “Tá com medinho de pegar vírus? Brincadeira. E o vírus é uma coisa que $60 \%$ vão ter, ou 70\%. [...] Eu desconheço qualquer hospital que esteja lotado.” (2 abr. 2020)

E10: "Eu não sou coveiro" (20 abr. 2020) (Resposta a pergunta de jornalista sobre o número crescente de mortos por COVID-19 no Brasil.)

E11: “A gente lamenta todos os mortos, mas é o destino de todo mundo." (2 jun. 2020) (Dito após uma apoiadora pedir uma palavra de conforto para as famílias em luto.)

E12: "É como uma chuva, vai atingir você" (7 jul. 2020) (Dito em entrevista na qual revelou ter testado positivo para COVID-19.)

E13: "País de maricas" (10 nov. 2020)

(Negrito nosso)

Que efeitos de sentidos predominam nesse corpus? Dois, que vão dar base a toda a argumentação do Presidente: a maximização das perdas da economia e a minimização da COVID-19. De acordo com o primeiro, as perdas econômicas provocadas pelo lockdown são mais importantes do que as humanas e devem ser evitadas (os itens lexicais, na maioria nomes e verbos, que produzem esse efeito são destacados em negrito): "alguns governadores, no meu entender, estão tomando medidas que vão prejudicar e muito a nossa economia"; "Algumas poucas autoridades, estaduais e municipais, devem abandonar o conceito de terra arrasada, a proibição de transportes, o fechamento do comércio e o confinamento em massa"; "Vão quebrar o Brasil por conta do vírus?" $O$ enunciador chega a indicar a cura pela atividade econômica numa frase que evoca $o$ slogan Arbeit macht frei ("O trabalho liberta"), exposto nos campos de concentração nazistas: "O maior remédio para qualquer doença é o trabalho".

Já o efeito de minimização reduz não só os sentidos da doença, mas da morte, do luto e dos próprios brasileiros. "Está superdimensionado o poder destruidor desse vírus", "Outras gripes mataram mais do que essa", "gripezinha", "resfriadinho" são enunciados que apresentam a COVID-19 como enfermidade menor usando diminutivos e a comparação com outras "gripes", mas sem especificá-las. Algumas expressões normalizam a alta transmissão sem apresentar dados científicos, apenas números aleatórios - "E o vírus é uma coisa que 60\% vão ter, ou 70\%" - ou o lugar comum: "É como uma chuva, vai atingir você". O brasileiro é representado como um ser imune a doenças que dispensa maior atenção das autoridades, imagem reduzida e caricatural, comum no discurso das elites sobre os pobres: "Brasileiro pula em esgoto e não acontece nada". Quem vê gravidade na pandemia e/ou toma medidas para contê-la é qualificado(a) com itens lexicais pejorativos: "Esse vírus trouxe uma certa histeria"; "Vamos ter que enfrentá-lo, mas enfrentar como homem, porra. Não como um moleque."; "Tá com medinho de pegar vírus?"; "País de maricas". A morte e o luto são tratados de forma banal e indiferente e também minimizados por lugares comuns: 
"Eu não sou coveiro"; "A gente lamenta todos os mortos, mas é o destino de todo mundo"; "É a vida. Todos nós iremos morrer um dia."

A maximização das perdas econômicas e a minimização da pandemia e da morte apoiam uma à outra. Para a FD que governa a produção desses enunciados, deve-se, acima de tudo, cuidar da saúde da Economia. As mortes são um fato natural e banal, problema de coveiro, não de governo. Os fatos sócio-históricos da morte e do luto são secundários e supérfluos. O movimento analítico entre o mesmo (paráfrase) e o diferente (polissemia) (ORLANDI, 1999) mostra outros sentidos possíveis, mas não ditos ou silenciados nesse discurso. Por exemplo, o enunciado "É a vida. Todos nós vamos morrer um dia" pode ter como paráfrase "A vida é assim. Ninguém é eterno", mas numa formulação orientada por outra FD, em relação a outra formação ideológica, os termos "vida" ou "morte" poderiam ser substituídos por designações econômico-políticas.

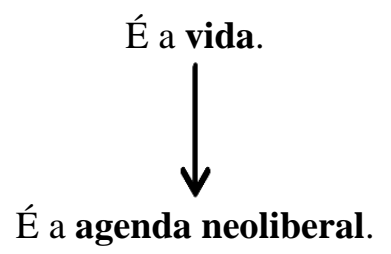

A polissemia escancara a relação da pandemia com um modelo econômico, o neoliberalismo: não se trata de uma questão meramente biológica, mas de como um fato biológico é gerido por uma política de governo para a qual a vida é secundária. Aparece aí outra posição na história, outro recorte na memória discursiva.

O segundo conjunto de discursos analisado é não-verbal, uma série de fotografias que registram ações do Presidente durante a pandemia.

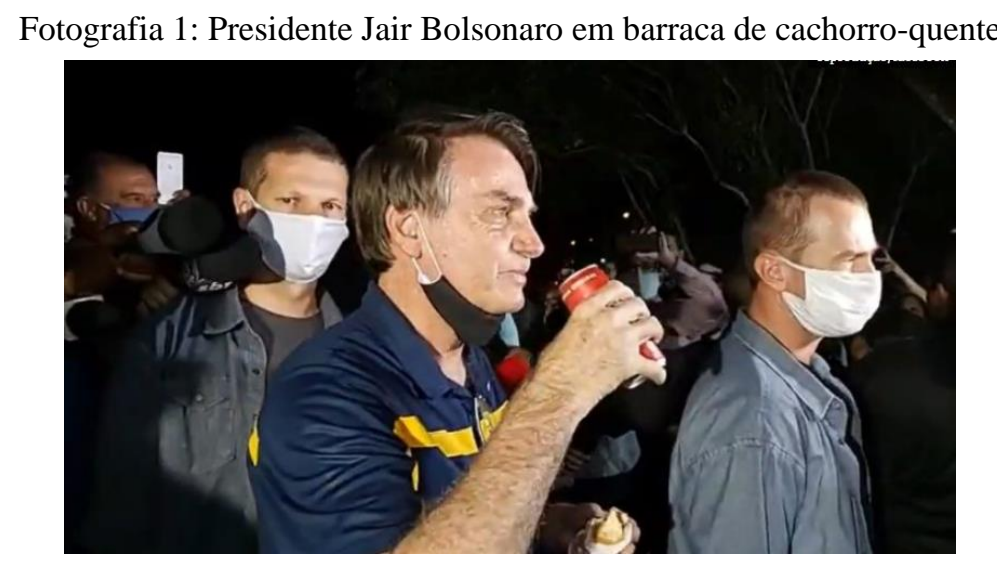

Fonte: Bolsonaro [...] (23 maio 2020).

Fotografias 2 e 3: Em frente ao Palácio do Planalto, Bolsonaro monta em um cavalo da PM e depois sobrevoa a Praça dos Três Poderes a bordo do helicóptero da Força Aérea 


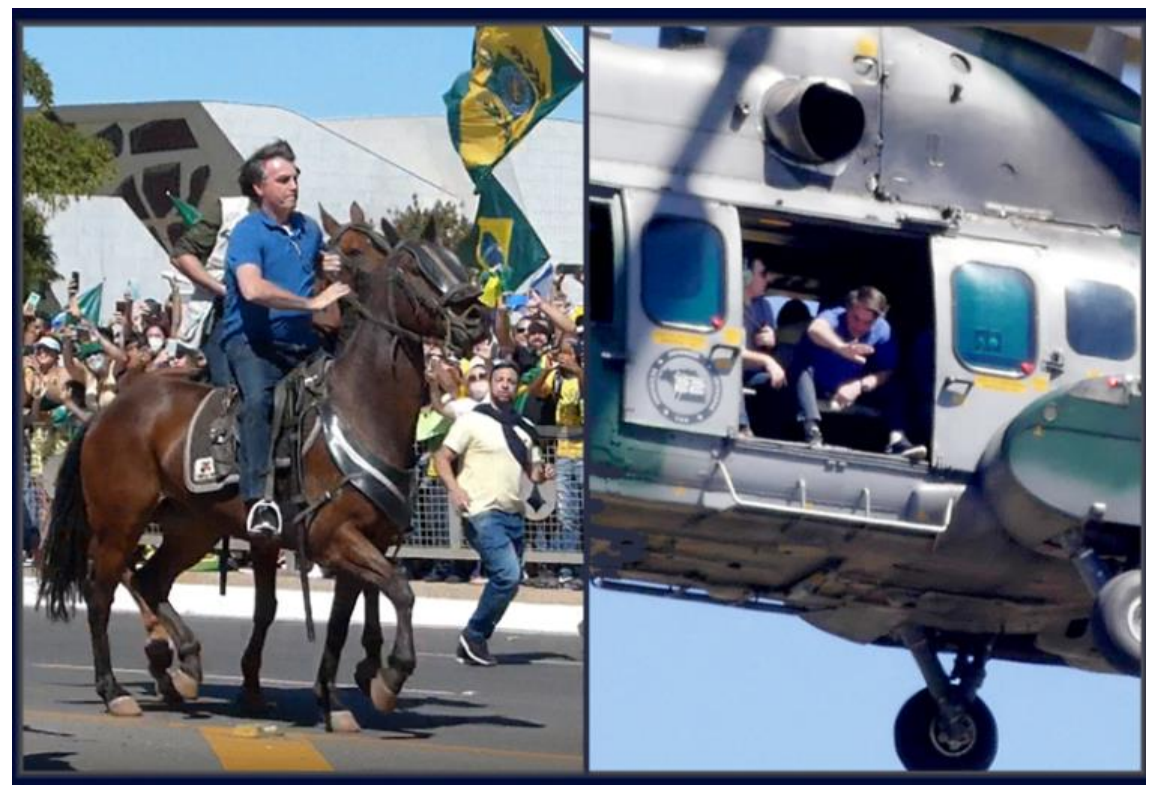

Fonte: Brito (31 maio 2020).

Fotografia 4: Bolsonaro se encontra com banhistas na Praia Grande em $1^{\circ}$ de janeiro de 2021

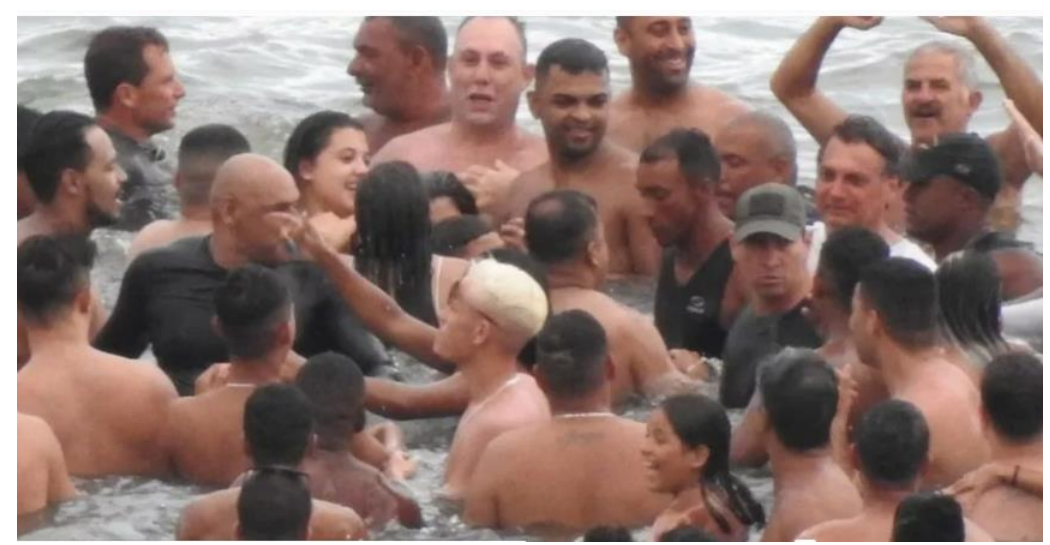

Fonte: Sem usar [...] (2 jan. 2021).

Fotografia 5: Bolsonaro comemora seu aniversário de 66 anos

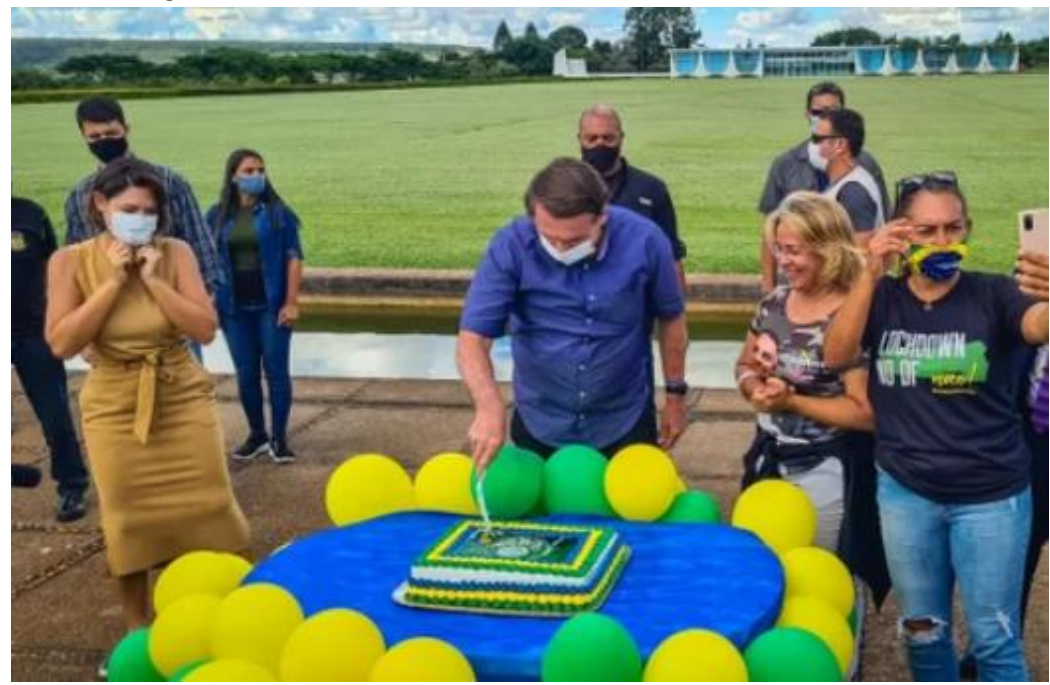

Fonte: Froufe e Warth (21 mar. 2021). 
Fotografia 6: Bolsonaro retira máscara de criança em Jucurutu (RN)

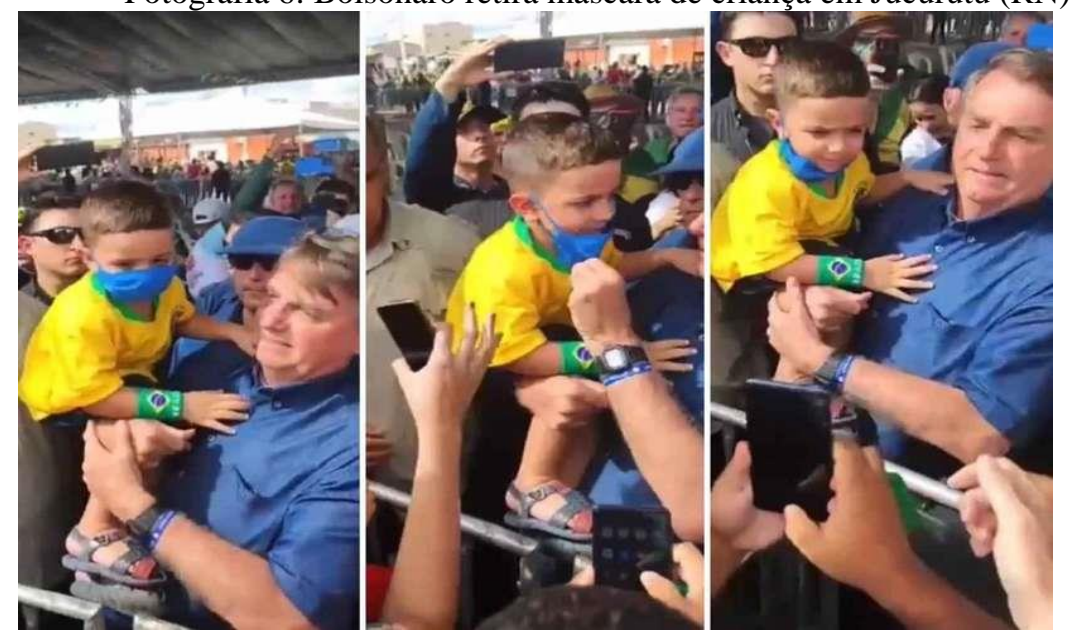

Fonte: Mendonça (24 jun. 2021).

Esses registros foram feitos por fotojornalistas e anônimos e têm diferentes resultados, mas o foco da análise não é a materialidade fotográfica e sim o objeto das fotografias: as ações e gestos do Presidente que elas mostram. Esses gestos produzem determinados efeitos. Bolsonaro geralmente aparece em aglomerações sem máscara ou cercado por pessoas sem máscara. Cidadãos comuns se aglomeram sem máscara por sua conta e risco, mas de um Presidente o imaginário burguês democrático espera atenção ao bom senso e às normas sanitárias. Bolsonaro confronta esse imaginário e instituições como a OMS, que estabelecem as normas.

As fotografias 2 e 3 registram os efeitos de um duplo enfrentamento: às normas sanitárias e aos adversários políticos do Presidente, porque foram feitas numa manifestação do líder do Executivo contra os outros dois poderes da República. Sem máscara, Bolsonaro desfila montado num cavalo, confrontando o Congresso e a Suprema Corte como um novo Napoleão ou César (fotografia 2). O encontro sem distanciamento com banhistas na Praia Grande (fotografia 4) também lembra uma ação de outro famoso líder autoritário, Mussolini (BITTENCOURT, 2021). Na fotografia 6, Bolsonaro vai além e tira a máscara de um menino que segura nos braços, o que torna o ato ainda mais afrontoso para quem se situa fora do seu campo discursivo. A fotografia 5, da sua festa de aniversário de 66 anos, é a única do conjunto em que Bolsonaro aparece de máscara; porém, a comemoração acontece quando são contados 300 mil mortos, produzindo um efeito de indiferença à pandemia, às vítimas e aos enlutados.

Em todos esses exemplos, Bolsonaro demonstra bem o papel do político como porta-voz da opinião pública, mediador entre o grupo que representa e o poder ou adversário (ZOPPI-FONTANA, 1997). O porta-voz é

[...] ao mesmo tempo ator visível e testemunha ocular do acontecimento: o efeito que ele exerce falando "em nome de..." é antes de tudo um efeito visual, que determina esta conversão do olhar pela qual o invisível do acontecimento se deixa enfim ser visto: o porta-voz se expõe ao olhar do poder que ele afronta, falando em nome daqueles que ele representa, e sob o seu olhar. Dupla visibilidade (ele fala diante dos seus e parlamenta com o adversário) que o coloca em posição de negociador potencial, no centro visível de um "nós" em formação e também em contato imediato com o adversário exterior. (PÊCHEUX, 1990, p. 17, negrito nosso).

O porta-voz Bolsonaro se materializa na justaposição de falas e gestos que configuram seu "corpodiscurso" (LEONEL, 2010), um corpo enquanto discurso que afronta e despreza as normas sanitárias, a democracia burguesa, as vítimas e os enlutados. Nessa região de sentidos da qual Bolsonaro enuncia não há lugar para homenagear mortos 
ou elaborar o trabalho de luto. A menção às milhares de mortes seria um contrassenso: o enunciador quer o país em plena produção mesmo durante a pandemia. $\mathrm{O}$ discurso neoliberal, autoritário e negacionista que o Presidente representa dá primazia para o lucro e ignora o outro e sua dor, que são silenciados, censurados.

Segundo Orlandi (1997, p. 132), a censura trabalha sobre o que é suposto que o sujeito saiba. Ela busca impedir a elaboração histórica dos sentidos e o movimento de identificação dos sujeitos. No grave contexto da pandemia - política frágil de combate ao coronavírus, economia nacional em declínio e, sobretudo, a massiva quantidade de vítimas fatais -, os gestos e pronunciamentos do Presidente da República silenciam/censuram a tragédia social e o luto, acontecimentos que são politicamente destrutivos para ele. Bolsonaro também não fez homenagens oficiais aos mortos e enlutados. Em agosto de 2020, quando se atingiu a marca de 100 mil mortes, apenas o Congresso e o STF (Supremo Tribunal Federal) decretaram luto oficial e publicaram notas de pesar (OLIVEIRA, 2020). Ainda que tenham sido atos protocolares, contrastaram com o silêncio do Poder Executivo.

\section{A RESISTÊNCIA DOS CHARGISTAS}

Onde há censura há possibilidade de falha, de resistência. A linguagem é passível de jogo, equívocos e deslocamentos que permitem a divergência. Um dos principais focos de resistência à política silenciadora de Bolsonaro se encontra no campo da arte, em particular na charge.

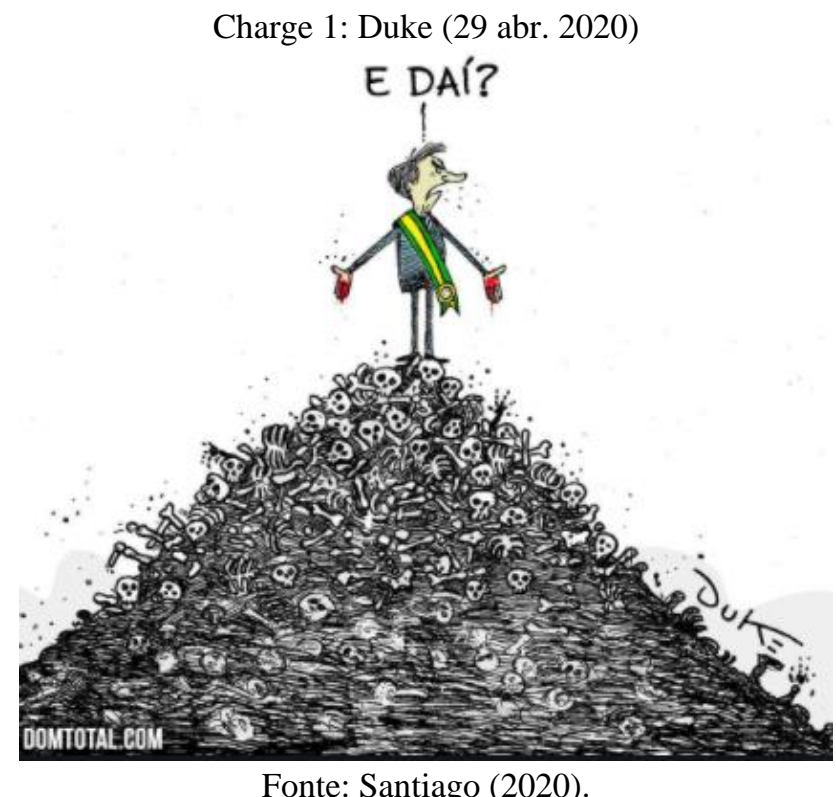

Fonte: Santiago (2020).

A charge 1, de Duke, que concorreu na $42^{\mathrm{a}}$ edição do Prêmio Vladimir Herzog (SANTIAGO, 2020), ataca a fala irônica e cruel do Presidente após ser questionado sobre os mais de 5 mil brasileiros mortos por COVID-19: "E daí? Lamento. Quer que eu faça o quê? Eu sou Messias, mas não faço milagre." Na charge, mais da metade do espaço é ocupada pelo monte de esqueletos que, sob os pés de Bolsonaro, desafia sua frase " $\mathrm{E}$ daí?". As mãos sujas de sangue também explicitam sua responsabilidade pelas mortes. 
Charges 2, 3, 4 e 5 (sentido horário): Latuff (2020-2021)

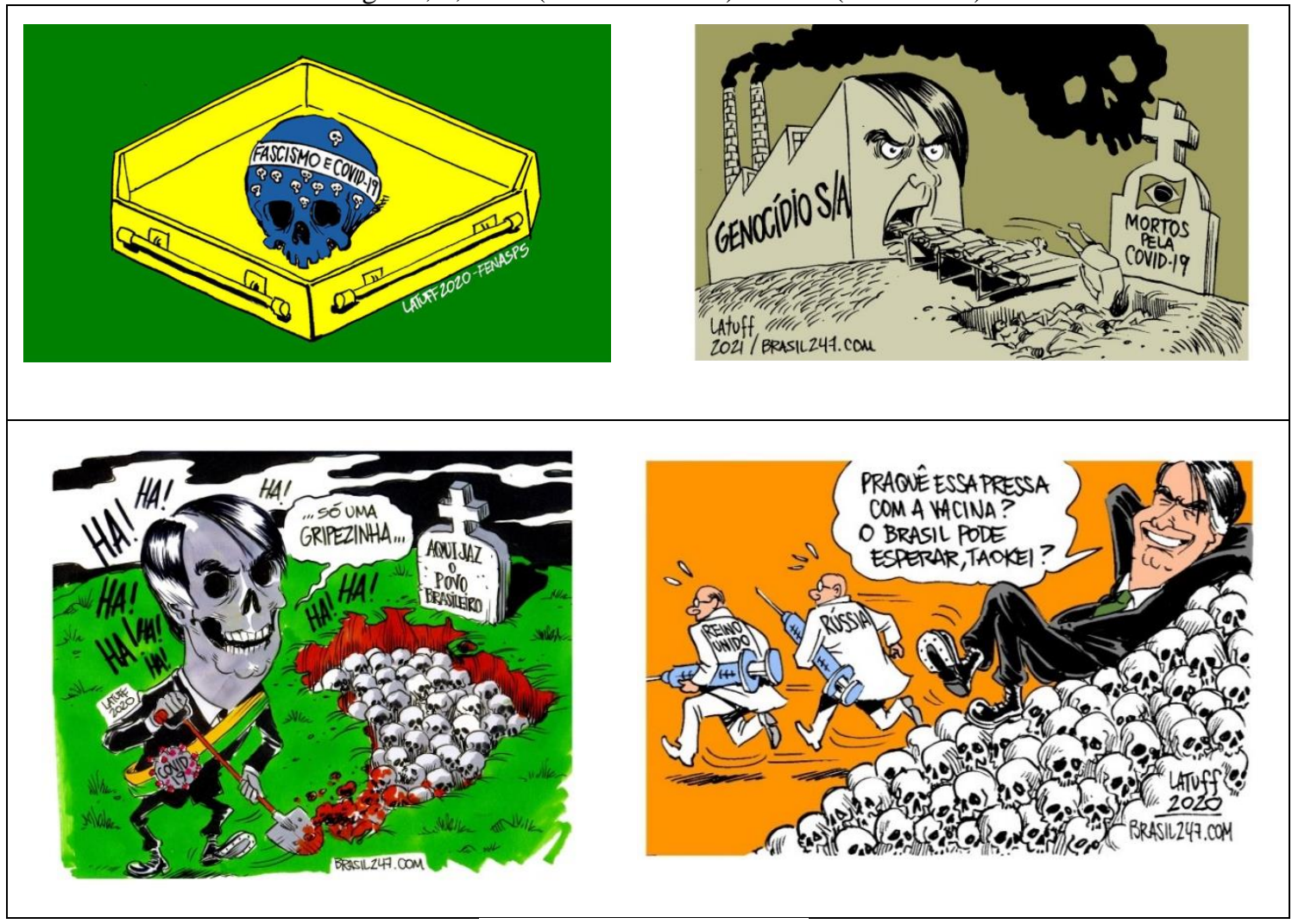

Fonte: Latuff (2020, 2021).

Na charge 2, o artista faz alterações nos elementos da bandeira do Brasil para que ela se torne um símbolo de morte: o losango amarelo se transforma num caixão e o círculo azul, num crânio; o lema "Ordem e Progresso" muda para "FASCISMO E COVID-19" e as estrelas são substituídas por pequenos crânios. A charge 3 funde a figura de Bolsonaro à de uma fábrica cujo nome é "GENOCÍDIO S/A", especializada na produção de mortos, que saem da sua boca num ritmo fordista. O Presidente tem um olhar mau e o cabelo evoca o de Hitler, mais uma referência ao fascismo, dessa vez imagética e não por palavra, como a da charge 2 . Na charge 4 o cartunista critica a recusa do governo a comprar vacinas do Reino Unido e da Rússia (representadas pelos enfermeiros que fogem), o que levou à morte milhares de brasileiros, simbolizados pelo monte de crânios sobre o qual o Presidente descansa e debocha da pressa. A charge 5 confronta declarações do Presidente Bolsonaro com as imagens: ele tinha dito que não era coveiro e o cartunista o representa como um coveiro com face de caveira que enterra as vítimas numa cova com a forma do território brasileiro. A faixa presidencial tem um coronavírus no lugar do brasão da República e entre risos debochados ele diz “...só uma GRIPEZINHA...”, outra fala famosa de Bolsonaro desmentida pela mortandade. Tanto na charge 4 como na 5 Bolsonaro calça botas militares com sola de ferradura, uma sátira à burrice ou irracionalidade do presidente militarizado.

O governo Bolsonaro tentou censurar pelo menos um dos cartunistas que o criticaram. Quando, em junho de 2020, o Presidente ordenou que seus seguidores invadissem hospitais e desmascarassem o que ele chamava de "farsa da pandemia", que os hospitais não estavam cheios de pacientes de COVID-19, o cartunista Renato Aroeira fez a charge intitulada "Crime continuado", em que um Bolsonaro vândalo transforma a cruz (símbolo dos hospitais) numa suástica (símbolo do nazismo) e diz "Bora invadir outro?" (charge 6). O governo retaliou acionando a Polícia Federal, que abriu inquérito 
contra Aroeira. Num gesto de solidariedade ao chargista e de resistência à intimidação de Bolsonaro, vários cartunistas produziram suas versões da charge com pequenas alterações (GOMES, 2020).

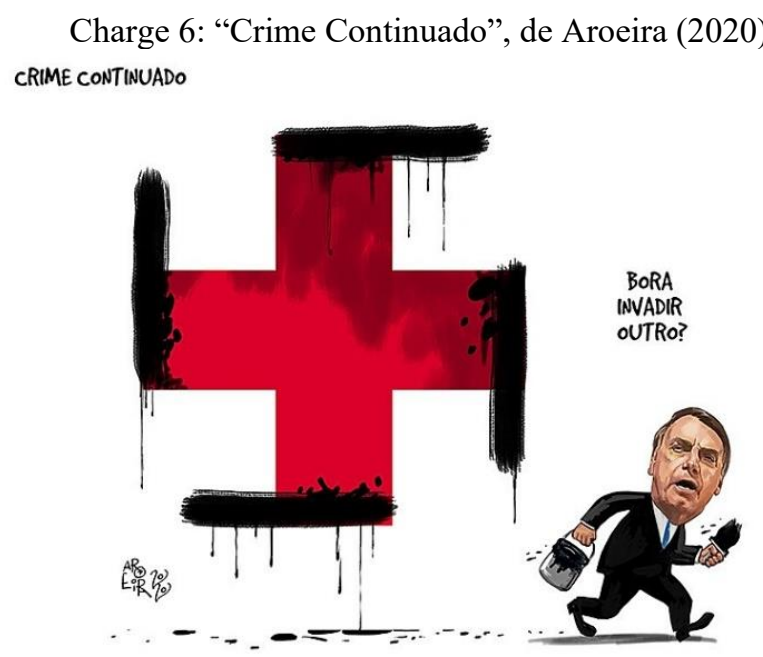

Fonte: Gomes (2020).

"Mudar, desviar, alterar o sentido das palavras e das frases; tomar enunciados ao pé da letra; deslocar as regras na sintaxe e desestruturar o léxico jogando com as palavras" (PÊCHEUX, 1990, p. 17) são formas de resistência da e na língua. No caso da charge, que é um gênero de materialidade mista, verbal e não-verbal, recorre-se também aos jogos com as formas visuais. Latuff transforma a bandeira nacional num símbolo da morte e põe uma franja hitleriana em Bolsonaro. Com algumas pinceladas, Aroeira faz da cruz uma suástica. Duke e Latuff confrontam e desconstroem falas do Presidente com imagens de pilhas de ossos. Latuff reformula o lema da bandeira nacional como "FASCISMO E COVID-19". A resistência das/nas charges, seja por meio visual ou verbal, diz/mostra de forma estética o que o governo silencia e censura: ele tem uma política de perfil nazifascista e negacionista que desdenha dos doentes e mortos, produzindo um genocídio.

\section{A RESISTENNCIA DOS ENLUTADOS}

O luto exige rituais, como o velório e a missa de sétimo dia, que ajudam a elaborar a perda. Com as normas sanitárias da pandemia, as visitas aos doentes e os velórios ficaram limitados. Parte da população buscou novas formas de viver e significar o luto diante da impossibilidade de velar adequadamente seus mortos. Uma dessas formas é o memorial, espaço ou objeto simbólico para preservar a memória de lugares, pessoas e acontecimentos por vezes traumáticos, como o Memorial de Auschwitz-Birkenau, dedicado ao Holocausto, ou o Memorial da Resistência de São Paulo, que, localizado numa antiga prisão, honra a memória dos que resistiram ao autoritarismo no Brasil.

O Memorial In-finito (fotografias 7 e 8) é uma obra arquitetônica construída no Rio de Janeiro em 2020. Nela estão inscritos os nomes de vítimas da COVID-19. Além de prestar homenagem aos mortos, o memorial pretende eternizar a memória das vítimas, o que se materializa no seu nome polissêmico "in-finito". Segundo a arquiteta responsável pelo projeto, Crisa Santos,

Este memorial foi concebido para homenagear todas as pessoas que não tiveram o direito de se despedir das pessoas que amam, através dos ritos fúnebres. A idealização da obra a céu aberto 
foi para oferecer um local em que os visitantes possam meditar e se conectar com quem partiu. Isso ajuda a ressignificar a morte, especialmente na pandemia, que inviabilizou as despedidas. Que ele seja uma peça importante na passagem, não simplesmente mais um número. Não é um número; são histórias que precisam ser perpetuadas, contadas. Daí a criação do memorial ser em onda que parece não ter fim. É exatamente isso: a nossa história não tem fim e não pode, simplesmente, acabar numa pandemia. Ela continua nos nossos familiares, nos nossos filhos, nos amigos, colegas de trabalho. São pessoas, histórias e não números. (CAMPBELL, 2020, negrito nosso).

Porém, como a homenagem é física, tem um custo, o que a restringe a quem pode pagar: "[a]s famílias que quiserem ter o nome de seus parentes na obra têm que apresentar a certidão de óbito com a causa da morte pela covid-19 e pagar uma taxa de R\$125", valor "referente à confecção do adesivo com nome que é colocado na obra" (CAMPBELL, 2020). Pessoas que estão sofrendo procuram o serviço com a expectativa de atenuar sua dor:

\begin{abstract}
A mãe da aposentada Maria Celina Muniz Barreto, 68, foi infectada pelo novo coronavírus e não resistiu. A filha diz que o memorial deve amenizar "um pouco" o luto. "Eu perdi minha mãe para a Covid-19 no dia 28 de maio. Além do enorme sofrimento com a morte, não poder me despedir foi um desalento. A tristeza assumiu uma força tão grande que aumenta a dor e a sensação do luto, que eu espero poder atenuar com essa homenagem." (CAMPBELL, 2020, negrito nosso).
\end{abstract}

Usando vocabulário psicanalítico, a fala da arquiteta se situa numa FD que compreende o ser humano como sujeito que atribui sentidos à vida e à morte e precisa do luto e da memória: "[o memorial] ajuda a ressignificar a morte, especialmente na pandemia, que inviabilizou as despedidas." Ela aborda a necessidade de se tratar o morto como pessoa que é também uma história e não simples estatística, o que se acentua no contexto da pandemia, em que morrem milhares diariamente: "São pessoas, histórias e não números". Lembremos que as falas do Presidente tratam as vítimas apenas como números ao dizer que 60 ou $70 \%$ das pessoas terão a doença e que não é coveiro para contar os mortos. A importância subjetiva e terapêutica fica bem clara no discurso da enlutada, que relata o "desalento" por não ter podido se despedir e espera "amenizar "um pouco' o luto" com a homenagem.

A produção do memorial e as falas da arquiteta e da enlutada mostram que se a COVID-19 impôs restrições à despedida dos entes queridos e ao luto, não impede o movimento dos sentidos. O luto não vivido plenamente pode encontrar outras formas de elaboração.

Fotografias 7 e 8: Memorial In-finito
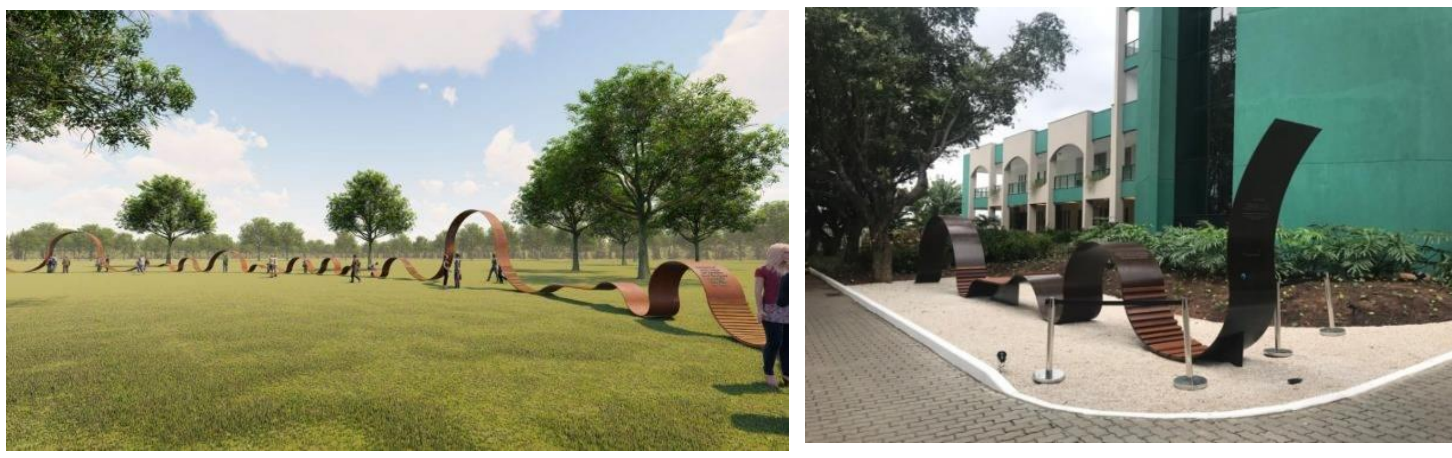

Fonte: Abdalla (2020). 
O outro memorial, o website Inumeráveis (inumeraveis.com.br), foi criado em 2020 pelo artista Edson Pavoni em colaboração com jornalistas e outros voluntários. Permite a participação gratuita de qualquer enlutado. Ele é descrito como "Memorial dedicado à história de cada uma das vítimas do coronavírus no Brasil" (print 1, negrito nosso). Perto do fim da página encontra-se a seguinte formulação: "não há quem goste de ser número/gente merece existir em prosa" (print 2, negrito nosso). Daí vem um dos sentidos do nome Inumeráveis: adjetivo que significa o que não é passível de ser numerado. O símbolo de infinito, presente na página, reforça esse sentido (print 2).

Prints 1 e 2: apresentação e narrativas do website Inumeráveis

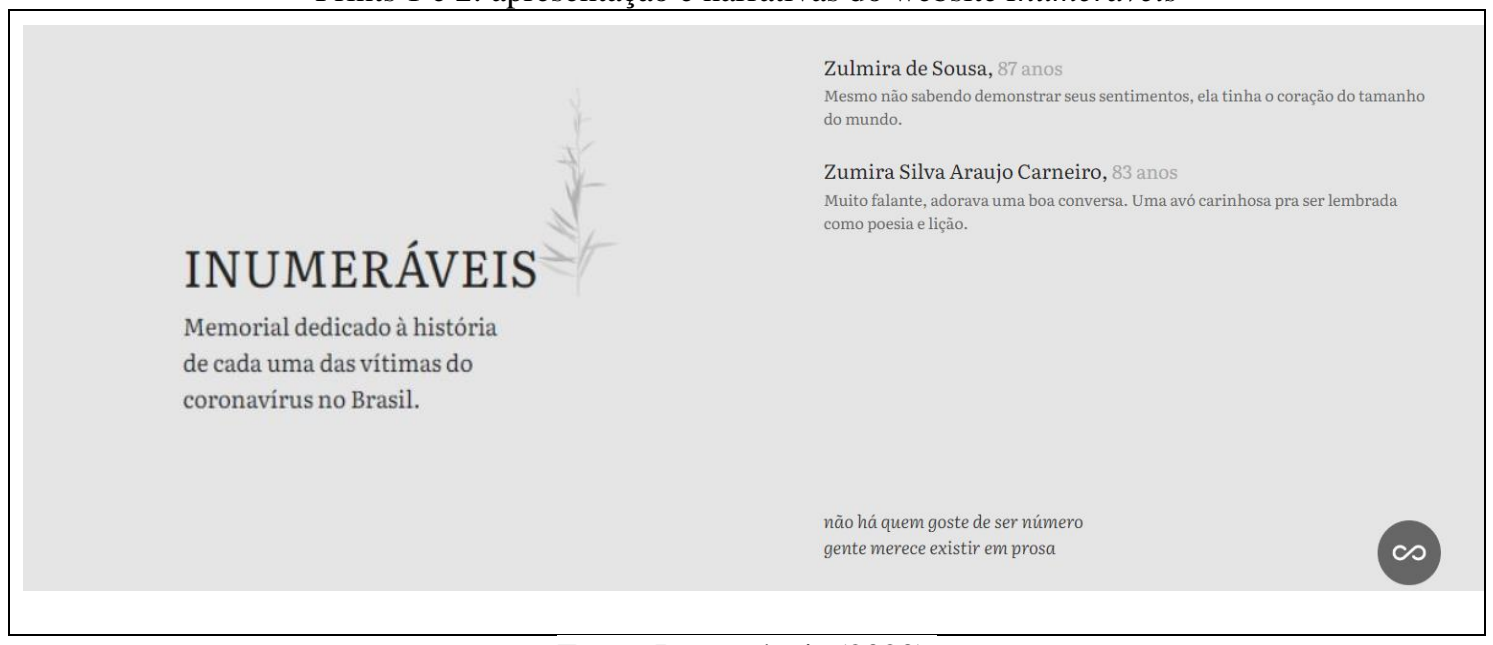

Fonte: Inumeráveis (2020).

O memorial traz textos biográficos preparados pela equipe do site com base em relato oferecido por pessoa próxima do falecido. Na página inicial, onde os nomes aparecem organizados por ordem alfabética, se vê apenas o início da biografia (print 2); se o leitor quiser ler mais, é preciso clicar no nome ou no início do texto. Portanto, é possível fazer duas leituras: a completa ou a do início apenas. Os textos não são relatos frios, exprimem afetividade e têm qualidades estéticas: "Zulmira Silva Araújo Carneiro, 83 anos - Muito falante, adorava uma boa conversa. Uma avó carinhosa para ser lembrada como poesia e lição." (print 2).

Como no Memorial In-finito, no modo de constituição do memorial Inumeráveis há um discurso sensível ao sujeito simbólico, que é significado como "história" que "merece existir em prosa", não como simples número. Se, como escreve Orlandi (2001, p. 193), “[f]ormular é textualizar palavras, é dar corpo aos sentidos", o memorial dá corpo simbólico-histórico às vítimas e auxilia o trabalho do luto, necessário para elaborar a perda. Barthes (2011) diz que uma das formas do trabalho do luto é a escritura, um modo outro de recriação do objeto perdido. A inscrição do significante sobre o ausente pode favorecer o princípio de realidade que, segundo Mannoni (1995), permite que o sujeito compreenda que o objeto realmente desapareceu. $O$ sujeito enlutado se fortalece na ressignificação pela escrita.

Ambos os memoriais funcionam como lugares de resistência à banalização da morte, à negação do luto e à própria morte, fato trans-histórico que desafia a memória humana. Rompem o silêncio sobre as vítimas e o luto e possibilitam que os sujeitos enlutados inscrevam seus mortos em espaços que são também estéticos e, por isso, perenes. O Memorial In-finito, onde estão inscritos os nomes de vítimas, é uma obra de arte arquitetônica e os textos do Inumeráveis são biografias, uma forma literária ancestral. A formulação artística transforma a experiência traumática, que é simbolicamente elaborada e adquire beleza e eternidade. 
Transformar a dor e a ausência em beleza, buscar a estética dos sentimentos por meio das criações artísticas. Utilizar-se das nossas subjetividades, nossas visões, nossa poética sobre a existência e abraçar a emersão de nossas memórias é dar ao tempo a função de gestar um novo significado para o luto, para a ausência. (CRUZ, 2020, p. 146).

\section{CONSIDERAÇÕES FINAIS}

O luto é um processo simbólico e histórico indispensável na vida de indivíduos e sociedades. Ele existe porque há vínculo, afetos, trocas, histórias compartilhadas, amor. Deve não apenas ser vivido como respeitado. A análise trouxe alguns elementos importantes para compreendermos o modo de significação do luto no contexto brasileiro da pandemia de COVID-19. A pandemia e o modo como é gerida pelas autoridades governamentais trouxeram grandes obstáculos para o luto.

O Presidente Jair Bolsonaro produz falas e gestos que materializam uma política de negação da pandemia e do trabalho de luto coletivo. Ele festeja, sai para comer cachorro-quente, desdenha da Ciência, tira a máscara de uma criança e ameaça um golpe de Estado, entre outras ações afrontosas às normas sanitárias, aos enlutados e até à democracia burguesa que ele representa. Essas ações e falas se fundam numa FD que maximiza as perdas da economia e minimiza a pandemia e as perdas humanas. Nada justifica parar a economia capitalista (o trabalho chega a ser significado como "o melhor remédio" para todos os males) e a morte é banalizada. Os sentidos que se opõem à política do porta-voz precisam ser silenciados e combatidos. Ele não fala da e nem lamenta a tragédia: antes, chama de "maricas" quem teme e respeita o vírus.

Por sua vez, as restrições sanitárias dificultam ou impedem as despedidas dos entes queridos e os velórios. As autoridades deveriam considerar o problema e buscar atenuar a dor dos enlutados, mas, aparentemente, isso é secundário para elas. O máximo que fazem é lamentar e decretar luto oficial. O Poder Executivo federal não chegou nem a decretar luto. A indiferença à mortandade e aos efeitos que ela produz compromete o trabalho do luto, o que, para a Psicanálise, resulta em mal-estar ou trauma coletivo de graves consequências para indivíduos e sociedades. Os gestos e símbolos do e para o luto, como homenagens às vítimas, memoriais, decretos de luto, testemunhos e escutas contribuem para a historicização da perda e trauma coletivos.

Nesse contexto não se reconhece e não se faz o luto sem resistência, embate, disputa de sentidos. Destacam-se as manifestações de artistas sensíveis ao mal-estar social, que resistem ao silêncio das autoridades. A textualização, a colocação do luto em palavras e outros signos mostra sua relação necessária não somente com o desejo, mas também com o político: “[e]m todo dizer há confronto com o político: todo dizer tem uma direção significativa determinada pela articulação material dos signos com as relações de poder." (ORLANDI, 2001, p. 129). Com suas obras verbovisuais, os cartunistas explicitam e denunciam o descaso e o autoritarismo com os quais o Presidente lida com a pandemia. Os artistas que criaram os memoriais às vítimas da COVID-19 pretendem resistir ao esquecimento dos mortos tratando-os não como números, mas "histórias" ou "prosa". Apesar dos diferentes objetos e materialidades dessas manifestações, todas elas resistem de forma estética ao silêncio, ao fascismo, à banalização da morte associados à pandemia e à política negacionista.

No caso dos memoriais também se pode dizer que resultam de um movimento ou "migração dos sentidos" (ORLANDI, 1997) do luto. Diante das restrições sanitárias e do grande número de vítimas fatais que banalizou a pandemia, o luto migrou, isto é, encontrou novos meios de formulação (arquitetura no Memorial In-finito e escritura 
biográfica no Inumeráveis) e circulação (espaço urbano e website). A migração de sentidos é resultado da necessidade histórica de simbolizar (ORLANDI, 2001). Se certos modos de formulação ou circulação forem impossibilitados, os sentidos buscarão outros. As condições históricas produzem aqui um funcionamento específico: o luto como resistência. Diante da interdição sanitária e da negação governamental, o luto migra para outros lugares e formas, garantindo aos mortos e enlutados visibilidade, eternidade e beleza pela inscrição nas formas estéticas da arquitetura e da escritura

Por fim e reiterando: o luto é o preço do amor. Se há luto, é porque há vínculo, afetos, trocas, histórias compartilhadas que enlaçam os sujeitos. Por isso o luto precisa não só ser vivido como respeitado. Se, por causa da pandemia, ele mal pode ser vivido e, para piorar, não for respeitado pelo porta-voz da nação, as perspectivas são sombrias. A resistência, seja por meio da sátira e da ironia das charges, seja por meio dos espaços onde ainda se pode viver o luto, mesmo que precariamente, torna-se fundamental para garantir respiro subjetivo e político para indivíduos e para a coletividade.

\section{REFERÊNCIAS}

ABDALLA, Sharon. Brasil tem primeiro monumento às vítimas da Covid-19 inaugurado no Rio de Janeiro. Gazeta do Povo, Curitiba, 21 set. 2020. Disponível em:

https://www.gazetadopovo.com.br/haus/arquitetura/brasil-monumento-vitimas-covid-19-inaugurado-rj/. Acesso em: 30 mar. 2021.

ALLOUCH, Jean. A erótica do luto no tempo da morte seca. Tradução: Procópio Abreu. Rio de Janeiro: Companhia de Freud, 2004.

BARTHES, Roland. Diário de luto. 26 de outubro de 1977 - 17 de setembro de 1979. Tradução: Leyla Perrone-Moisés. São Paulo: Martins Fontes, 2011.

BIRMAN, Joel. Arquivos do mal-estar e da resistência. 2. ed. Rio de Janeiro: Civilização Brasileira, 2017.

BITTENCOURT, Julinho. Bolsonaro volta a imitar Mussolini ao nadar em praia lotada entre seguidores. Fórum, [S. l.] 2 jan. 2021. Disponível em: https://revistaforum.com.br/politica/bolsonaro-volta-aimitar-mussolini-ao-nadar-em-praia-lotada-entre-seguidores/\#. Acesso em 29 jun. 2021.

BOLSONARO sai para comer cachorro-quente e é alvo de panelaço em Brasília. Congresso em foco, Brasília, 23 maio 2020. Disponível em: https://congressoemfoco.uol.com.br/governo/bolsonarosai-para-comer-cachorro-quente-e-e-alvo-de-panelaco-em-brasilia/. Acesso em: 30 mar. 2021.

BRITO, Orlando. Bolsonaro, do lombo do cavalo ao banco do helicóptero - domingo, 31 de maio de 2020. Os Divergentes, Brasília, 31 maio 2020. Disponível em: https://osdivergentes.com.br/orlandobrito/bolsonaro-do-lombo-do-cavalo-ao-banco-do-helicoptero-domingo-31-de-maio-de-2020/. Acesso em $1^{\circ}$ abr. 2021.

BUARQUE, Chico. Pedaço de mim (1977). Letras de Chico Buarque. Disponível em: http://www.chicobuarque.com.br/letras/pedacode_77.htm. Acesso em: 30 mar. 2021.

CAMPBELL, Tatiana. Monumento em homenagem às vítimas da covid-19 é instalado no Rio. UOL, Rio de Janeiro, 20 set. 2020. Disponível em: https://noticias.uol.com.br/saude/ultimasnoticias/redacao/2020/09/20/monumento-vitimas-covid.htm. Acesso em: 31 mar. 2021.

COURTINE, Jean-Jacques. Définition d'orientations théoriques et construction de procédures en analyse du discours. Philosophiques, Québec, v. 9, n. 2, p. 239-264, oct. 1982. DOI https://doi.org/10.7202/203194ar. Disponível em: https://www.erudit.org/fr/revues/philoso/1982-v9-n2-philoso1303/203194ar/. Acesso em: 26 mar. 2021.

CRUZ, Mônica Lachman da. Poesia do luto através da imagem: uma visita aos campos da memória. Tuiuti: Ciência e Cultura, Curitiba, v. 6, n. 61, p. 122-147, 2020. DOI: https://doi.org/10.35168/2176896X.UTP.Tuiuti.2020.Vol6.N61.pp122-147. Disponível https://seer.utp.br/index.php/h/article/view/2509. Acesso em: 25 jun. 2021.

DUNKER, Christian Ingo Lenz. A cadeia dos lutos. Carta Maior, [S. l.] 6 jul. 2020. Disponível em: https://www.cartamaior.com.br/?/Editoria/Sociedade-e-Cultura/A-Cadeia-dos-Lutos/52/48040. Acesso em: 22 mar. 2021.

FREUD, Sigmund. Luto e melancolia. In: Escritos sobre a psicologia do inconsciente. Coord. geral da tradução: Luiz Alberto Hanns. Rio de Janeiro: Imago, 2006. v. 2, p. 99-122. 
FROUFE, Célia; WARTH, Anne. Bolsonaro comemora aniversário com apoiadores e diz que críticos estão "esticando a corda". GZH Política/Estadão Conteúdo, Porto Alegre, 21 mar. 2021. Disponível em: gauchazh.clicrbs.com.br/politica/noticia/2021/03/bolsonaro-comemora-aniversario-comapoiadores-e-diz-que-criticos-estao-esticando-a-corda-ckmjkikvv000q01f11ckztaei.html. Acesso em: 28 jun. 2021.

GOMES, Amélia. Aroeira sobre censura: "Oprimidos têm superioridade moral em relação a fascistas". Brasil de Fato, Belo Horizonte, 25 jun. 2020. Disponível em: https://www.brasildefato.com.br/2020/06/25/aroeira-os-oprimidos-tem-superioridade-moral-emrelacao-a-esses-canalhas-fascistas. Acesso em: 4 mar. 2021.

INUMERÁVEIS. Website memorial, 2020. Disponível em: https://inumeraveis.com.br. Acesso em: 23 mar. 2021.

KEHL, Maria Rita. O tempo e o cão: a atualidade das depressões. São Paulo: Boitempo, 2009.

KEHL, Maria Rita. "Talvez seja infindável o luto dos familiares”, diz Maria Rita Kehl. [Entrevista concedida a] Luiz Fernando Vianna. O Globo Época, Rio de Janeiro, 19 abr. 2020. Disponível em: https://oglobo.globo.com/epoca/talvez-seja-infindavel-luto-dos-familiares-dizmaria-rita-kehl-1-24382274. Acesso em: $1^{\circ}$ mar. 2021.

LATUFF, Carlos. Charges. Brasil 247, São Paulo, 2020-2021. Disponível em: https://www.brasil247.com/authors/carlos-latuff. Acesso em: 22 mar. 2021.

LEONEL, Levi. O corpo encarnado. Entremeios, Pouso Alegre, v. 1, n. 1, jul. 2010. Disponível em: http://ojs.univas.edu.br/index.php/revistaentremeios/article/view/25. Acesso em: $1^{\circ}$ mar. 2021.

MANNONI, Maud. O nomeável e o inominável: a última palavra da vida. Tradução: Dulce Estrada. Rio de Janeiro: Jorge Zahar, 1995.

MENDONÇA, Ana. Bolsonaro tira máscara de criança ao pegá-la no colo. Estado de Minas, Belo Horizonte, 24 jun. 2021. Disponível em: https://www.em.com.br/app/noticia/politica/2021/06/24/interna_politica,1280186/bolsonaro-tiramascara-de-crianca-ao-pega-la-no-colo-veja-o-video.shtml. Acesso em: 25 jun. 2021.

NASIO, Juan David. O livro da dor e do amor. Tradução: Lucy Magalhães. Rio de Janeiro: Jorge Zahar, 1997.

OLIVA, Gabriela. 251 mil mortes por COVID: relembre as falas de Bolsonaro sobre a pandemia. Poder 360, Brasília, 25 mar. 2021. Disponível em: www.poder360.com.br/1-ano-de-covid-nobrasil/251-mil-mortes-por-covid-relembre-as-falas-de-bolsonaro-sobre-a-pandemia/. Acesso em: 30 mar. 2021.

OLIVEIRA, Marina. Congresso e STF decretam luto oficial pelas 100 mil mortes por covid-19. Congresso em foco, Brasília, 8 ago. 2020. Disponível em: https://congressoemfoco.uol.com.br/saude/congresso-e-stf-decretam-luto-oficial-pelas-100-milmortes-por-covid-19/. Acesso em: 23 mar. 2021.

ORLANDI, Eni Puccinelli. Análise de Discurso: princípios e procedimentos. Campinas: Pontes, 1999.

ORLANDI, Eni Puccinelli. As formas do silêncio: no movimento dos sentidos. 4. ed. Campinas: Editora da Unicamp, 1997.

ORLANDI, Eni Puccinelli. Discurso e texto: formulação e circulação dos sentidos. Campinas: Pontes, 2001.

PÊCHEUX, Michel. Delimitações, inversões, deslocamentos. Tradução: José Horta Nunes. Cadernos de Estudos Linguísticos, Campinas, n. 19, p. 7-24, jul./dez. 1990. DOI https://doi.org/10.20396/cel.v19i0.8636823. Disponível em: https://periodicos.sbu.unicamp.br/ojs/index.php/cel/article/view/8636823/4544. Acesso em: 30 mar. 2021.

PÊCHEUX, Michel. Semântica e discurso: uma crítica à afirmação do óbvio. Tradução: Eni Orlandi e outros. Campinas: Editora da Unicamp, 1988.

PENNA, Carla. Investigações psicanalíticas sobre o luto coletivo. Cadernos de Psicanálise, Rio de Janeiro, v. 37, n. 33, p. 9-30, jul./dez. 2015. Disponível em: http://pepsic.bvsalud.org/scielo.php?script=sci_abstract\&pid=S141362952015000200001\&lng=pt\&nrm=iso\&tlng=pt. Acesso em: 26 mar. 2020.

RIVIÈRE, Claude. Os ritos profanos. Tradução de Guilherme João de Freitas Teixeira. Petrópolis: Vozes, 1997.

SANTIAGO, Isabela Amorim. Chargista Duke concorre na categoria arte do Prêmio Vladimir Herzog com trabalho feito no DomTotal. DomTotal, Belo Horizonte, 9 out. 2020. Disponível em: https://domtotal.com/noticia/1475719/2020/10/chargista-duke-concorre-na-categoria-arte-dopremio-vladimir-herzog/. Acesso em: 20 mar. 2021. 
SEM usar máscara, Bolsonaro pula de barco para falar com banhistas em Praia Grande. Tribuna de Jundiaí, Jundiaí, 2 jan. 2021. Disponível em: www.tribunadejundiai.com.br/mais/brasil/sem-usar-mascarabolsonaro-pula-de-barco-para-falar-com-banhistas-em-praia-grande/. Acesso em: 22 mar. 2021.

SOCIEDADE BRASILEIRA DE MEDICINA DE FAMÍLIA E COMUNIDADE. OMS declara pandemia de coronavírus: o que isso significa? Rio de Janeiro, 11 de março de 2020. Disponível em: https://www.sbmfc.org.br/noticias/oms-declara-pandemia-de-coronavirus-o-queisso-significa/. Acesso em: 27 mar. 2021.

VANNUCHI, Camilo. A pandemia de Covid-19 segundo Bolsonaro: da "gripezinha" ao "e daí?" UOL Notícias, [S. l.] 30 abr. 2020. Disponível em: https://noticias.uol.com.br/colunas/camilovannuchi/2020/04/30/a-pandemia-de-covid-19-segundo-bolsonaro-da-gripezinha-ao-e-dai.htm. Acesso em: 30 mar. 2021.

ZOPPI-FONTANA, Mónica Graciela. Cidadãos Modernos: discurso e representação política. Campinas: Editora da Unicamp, 1997.

Recebido: 6/4/2021

Aceito: $1 / 9 / 2021$

Publicado: 23/11/2021 